\title{
POTENCIAL FISIOLÓGICO DE ESPÉCIES OLERÍCOLAS SUBMETIDAS A DIFERENTES ESPECTROS DE LUZ
}

\author{
Mauricio Ferrari ${ }^{1}$ \\ Morgana Mattiello Baldin ${ }^{2}$ \\ Inana Xavier Schultze ${ }^{3}$ \\ Cintia Garcia ${ }^{4}$ \\ Bruna Possebon ${ }^{5}$ \\ Gustavo Sessa Fialho ${ }^{6}$ \\ Marcos Botton ${ }^{7}$ \\ Antonio Costa de Oliveira ${ }^{8}$ \\ Luciano Carlos da Maia ${ }^{9}$
}

\begin{abstract}
Resumo: O objetivo do trabalho foi avaliar o efeito de diferentes espectros de luz sobre o potencial fisiológico de espécies olerícolas. O experimento foi conduzido em delineamento inteiramente casualizado, no esquema fatorial três por cinco, com quatro repetições. As três espécies testadas foram alface (Lactuca sativa L.), rúcula (Eruca sativa Mill.) e couve chinesa (Brassica rapa var. pekinensis). Os cinco espectros de luz utilizados foram: vermelho, azul, amarelo, branco e ausência de luz. O teste de germinação foi conduzido em germinador tipo $B O D$, com temperatura constante de $25^{\circ} \mathrm{C}$. Para a alface o espectro azul revela efeito negativo sobre as variáveis primeira contagem, percentual de germinação e comprimento de radícula. Para espécies de rúcula e couve chinesa, o espectro de luz vermelha e amarela apresentaram os melhores resultados para as variáveis estudadas.
\end{abstract}

Palavras-chave: Brassica rapa; Eruca sativa; Filocromo; Germinação; Lactuca sativa.

\footnotetext{
${ }^{1}$ Universidade Federal de Pelotas, Faculdade de Agronomia Eliseu Maciel/Departamento de Melhoramento de Plantas, Brasil. E-mail: ferraritatu@gmail.com.

2 Universidade Federal de Pelotas, Faculdade de Agronomia Eliseu Maciel/Departamento de Fitossanidade, Brasil. E-mail: morgana.baldin13@gmail.com.

${ }^{3}$ Universidade Federal de Pelotas, Faculdade de Agronomia Eliseu Maciel/Departamento de Fitossanidade, Brasil. E-mail: i_schutze@hotmail.com.

${ }_{4}^{4}$ Universidade Federal de Pelotas, Faculdade de Agronomia Eliseu Maciel/Departamento de Melhoramento de Plantas, Brasil. E-mail: cintia.s.garcia@hotmail.com.

${ }^{5}$ Universidade Federal de Pelotas, Faculdade de Agronomia Eliseu Maciel/Departamento de Melhoramento de Plantas, Brasil. E-mail: possebonbruna@gmail.com.

${ }^{6}$ Universidade Federal de Pelotas//Instituto de Física e Matemática, Brasil. E-mail: gsfialho@hotmail.com.

${ }^{7}$ Pesquisador da Embrapa Uva e Vinho, Brasil. E-mail: marcos@enpuv.embrapa.br.

8 Universidade Federal de Pelotas, Faculdade de Agronomia Eliseu Maciel/Departamento de Melhoramento de Plantas, Brasil. E-mail: acostol@terra.com.br.

9 Universidade Federal de Pelotas, Faculdade de Agronomia Eliseu Maciel/Departamento de Melhoramento de Plantas, Brasil. E-mail: lucianoc.maia@gmail.com.
} 